\title{
A Contrastive Analysis on Web-based Intercultural Peer Feedback
}

\author{
Qin Wang \\ English Department, Foshan Radio and Television University \\ Renmin, Rd., Changchen District, Foshan, Guangdong, 528000, China \\ Tel; 86-13-516592161 E-mail: qinqinwang2002@163.com
}

Received: 29-06-2013

Accepted: 15-08-2013

Published: 01-11-2013

doi:10.7575/aiac.ijalel.v.2n.6p.111

URL: http://dx.doi.org/10.7575/aiac.ijalel.v.2n.6p.111

The present study is Co-sponsored by National Open University of China under the Youth Talent Project entitled "An Empirical Study of blog-assisted Second Language Writing"(Project code: Q2809A)and Guangdong Radio and Television University for the branch project entitled "Exploring Learning-oriented Writing Assessment Paradigm"(Project Code:YJ1306).

\begin{abstract}
This paper made a contrastive analysis on peer feedback generated by Chinese EFL learners and Native Speakers of English, who participated in a web-based Cross-Pacific Writing Exchange program. The analysis mainly focused on differences in terms of commenting size, nature and function; the pragmatic differences between two groups of learners were investigated as well. The present study afforded us lessons for peer review training program and provided pedagogical implications for L2 writing.
\end{abstract}

Keywords: peer feedback; web-based; intercultural; contrastive analysis

\section{Advantages and Significance of Peer Feedback}

Guided by process-based approach to L2 writing, feedback contributes to second language acquisition by involving students in revising drafts, negotiating and interacting with teachers or peers to improve students' self-presentation and productive text quality. Unlike traditional Peer feedback, peer feedback serves as a social interaction paradigm generated during the process of the text construction and joint negotiation among student writers and their peer readers.

Scholars abroad reached consensus, to some extent, on the positive impact of peer feedback on L1 and L2 writing. "Peer feedback facilitates to foster a sense of audience, raise learners' awareness of their own strengths and weaknesses, reduce writing anxiety and improve the quality of productive text" (Stanley 1992: 227). "It encourages cooperative learning, foster responsibility and ownership of text" (Tusi \&Ng 2000: 165). "It stimulates learners' positive perception on writing, increases writing motivation, contributes to L2 acquisition (Min 2005: 302)”. In other words, peer feedback contributed to foster learners' positive affect, including positive writing motivation, willingness to participate in collaborative learning and take responsibility for self-learning. These researchers mainly focused on EFL or ESL learners; however, few studies have been conducted on the effect of peer feedback on L1 writing.

In spite of the increasing interests for peer feedback research, a few scholars cast doubt on its effectiveness and quality. Some researchers pointed out, EFL and ESL learners are incapable of giving specific and effective feedback due to their inadequate language competence and discourse construction competence (Mangelsdorf\&Schlumberger,1992; Mendonca\&Johnson,1994;Tsui\&Ng,2000). Nelson and Murphy (1992) found that interaction within group were very likely to break down as a result of sharp, irony and unfriendly comments from their peers. On the contrary, Carson \& Nelson's (1998) research revealed that participants are reluctant to make critical comments in front of their peers lest they should embarrass their peers.

The aforementioned research findings indicated that the effectiveness and quality of feedback is subjected to various factors, such as students' personality, language proficiency, rhetorical competence and teachers' classroom interference in feedback process. Above all, the context of situation, which involves the application of teaching medium and facility, the implementation of learning activities, the combination of different peer feedback modes in different phases of classroom activity, also plays a pivotal role in peer feedback effectiveness.

Computer-Mediated Communication (abbreviated as CMC), creates context of meaningful negotiation, authentic interaction and atmosphere for communication. It not only reduced learners' anxiety learners experienced during faceto-face communication, boosted learners' confidence, it also increased the quantity of both peer feedback and teachers' feedback (Braine, 1997).4Breuch (2004) summed up the three major characteristics of web-based peer feedback as follows: 1) beyond its time constraints; real-time synchronous or delayed-time asynchronous, 2) beyond the limited circle of interlocutors of classroom pair and group work, and 3) interaction is based on text. Researchers believed web- 
based peer feedback bear the following advantages: "It could motivate learners to participate in peer feedback while composing essay, generate text with intense interaction, enable students to notice the writing features of their own writing and other peers, and encourage students to practice more writing (Mittan,1989; Ferris\& Hedgcock, 1998).

\section{Literature Review}

Concerning the pertinent studies in the past decade, a few researchers investigated the impact of different modes of peer review on learners' commenting behavior, L2 writing proficiency and learners' perception. Tuzi (2004) discussed the effect of an online writing system on ESL students' revision. His findings indicated web-based peer comments primarily focused on local textual features, such as paragraph, clause, sentence et al. Guardado and Shi (2007) argued that making peer comments via asynchronous CMC mode, students tended to balance positive and negative feedback and proposed specific revision suggestions. Chen (2012) studied the effect of blog-based peer feedback on academic English writing teaching, and Taiwan EFL learners' perceptions of blog-based peer feedback is investigated as well. The results revealed $74 \%$ of learners are in the belief that peer feedback in blogging context could enhance learners' writing proficiency. Moreover, the proposed suggestions are conducive to learners' revising their drafts. The majority of students are favorably disposed towards blog-based peer review.

Another strand of research has focused on the effect of peer review training on revision and quality of writing (Berg, 1999; Lion \& Peng, 2009; Min, 2006; Stanley, 1992). In addition, some researchers compared the effect of different modes of peer feedback (face-to-face communication, synchronous CMC and asynchronous CMC) on the quality and quantity of writing revision. These studies mainly focused on Chinese EFL learners or ESL learners abroad, who shared the same or similar linguistic and cultural background. As Nelson and Carson (1998:124) pointed out, "the homogeneity of language and culture ensures the successful progress of learning activities within group. Since it is beneficial for group members to achieve a better understanding of difference in communication and establish harmony within group".

To date, few researches have centered on mixed peer response groups. Zhu (2001) examined student interaction and feedback in mixed peer response group consisting of Native Speakers of English and Second Language learners; he conducted his study by inspecting participants' turn-taking behavior in oral discussion of peer's essay, language functions performed during peer response and written feedback on each other's writing. His findings indicated that nonnative speakers took fewer turns and produced fewer language functions during oral discussion of writing, but the ESL students offered a rather similar amount of global feedback as the native speakers in the written mode of peer response. He argued that the ESL students made valuable contributions to peer response, particularly through providing written feedback although their participation in oral discussion of writing was more limited compared to that by native speakers.

L2 writing research has addressed the challenges associated with peer interaction in the L2 setting. A few researches have addressed the issue of challenges in mixed response group. L2 learners with diverse levels of linguistic and cultural /pragmatic skills were involved in peer interaction; their different communication styles, expectations and attitudes towards group norm posed great challenges to peer response task (Allaei \& Connor, 1990; Cason \& Nelson, 1994; Nelson \& Carson, 1998; Nelson \& Murphy, 1992).

Compared with the previous peer feedback researches focused exclusively on ESL learners or Native Speakers of English, the study reported below aimed at broadening the existing peer feedback researches by comparing the peer feedback generated by Native Speaker of English and English as Foreign Language learners in China. The present study aims to bridge this gap via answering the following questions:

1) What are the differences between Native Speaker of English (NSE) group and English as Foreign Language (EFL) group learners in terms of area, nature and type of peer comments? Which factors contribute to those differences?

2) What are the pragmatic differences of peer comments generated by two groups of learners?

\section{Research Design}

\subsection{Participants}

The Chinese participants were 25 English major sophomores from a University in Guangzhou, including 9 males and 16 females. The participants on the American side were 30 sophomore students from a state University in Pennsylvania, including 12 males and 18 females. Different from their Chinese counterpart who major in English, they specialized in various fields.

The teachers in charge of this project divided all the participants into five groups after asking for their permissions. All the participants in this study have never received any training on peer feedback before.

\subsection{Peer Review Procedure}

In order to enhance Sino-US students' communication and cultural exchange, promote learners' ability to appreciate different genres of writing and facilitate English learners' language acquisition, our research team recruited college student volunteers in the two universities to participate in "write to learn" program, The supervisory team, which was made up of experienced writing instructors, established "Cross-Pacific Exchange Writing" website as the interaction platform for peer reviewing. Students could upload their own writing to the designated area only if they logged onto the website with the correct user name and password. Students were required to choose one out of the designated five topics. Each student was required to upload at least two essays within one month and provided comments on at least two group members' writings. The size of the writing was not stipulated. 
Students were required to give response and revise their first draft within two weeks after receiving peer comments. The peer review process lasted for 3 months. In the middle of each month, a teacher sent an online message to remind students to finish their assignments on time and kept records of their students' writing achievements.

\subsection{Data Collection and Analysis}

The text corpus consisted of students' writing samples downloaded from "Cross-pacific Writing Exchange" website. Peer comments from Chinese and American students' writing (50 from each group) were drawn at random. In order to compare peer feedback generated by two groups of learners, the current study adopted the classification applied in Liu and Sadler's (2003) study. The analysis and interpretation focused on how the comments from students were distributed in both global area (feedback with regards to idea development, audience and purpose, and organization of writing) and local area( feedback with regards to copy-editing, such as wording, grammar and punctuation); on the nature of comments(revision-oriented or non-revision oriented); on how the comments were distributed across four types of comments: evaluation (comments on either good or bad features of writing); clarification( probing for explanation and justification); suggestion (pointing out the directions for changes); and alteration ( providing specific changes).

To guarantee the preciseness and validity of data, the analysis procedure followed the following steps. First, label the text. Three English teachers did the pilot labeling on 10 writing samples drawn from two groups of peer comments, took sentence which is a semantic unit, as a unit for analysis. The agreement among 3 teachers in labeling text reached $97 \%$, which indicated that the labeling method is reliable and valid. Next, statistical analysis was conducted on the distribution of commenting area, nature and type within two groups of learners (EFL learners and NSE learners). The unit of analysis in EFL group amounted to 1435, while NSE group to 1580.

\section{Results and discussion}

\subsection{The Distribution of Peer Comments in Area, Nature and Type}

As shown in Table 1, the number of local comments made by the EFL group (58\%) is much larger than that of global comments (16\%). This data showed astonishing approximation to the result yielded in Zhu (2001)'s study, which found $58.3 \%$ (42 out of 72) of native speakers' comments were global. This finding also led a support to Chang(2009)'s claim that when Chinese EFL learners made peer comments via CMC mode, revision-oriented comments mainly focused on local textual features, such as clause, sentence, paragraph, et al.

On the contrary, the number of local comments made by the NS group (43.7\%) was smaller than that of global comments $(56.3 \%)$. In other words, the NS group produced relatively more global comments than the EFL group. This research finding, however, is different from that in Zhu's study, which found that non-native speakers provided as many global comments as native speakers did. It might be inferred that different participants ---EFL learners who went through individual L2 learning experience and acquired different levels of L2 expertise from ESL learners, and different mode of peer feedback interaction coordinately play a contributing role in reaching different conclusions.

Table 1: The Dccutrence aud Percentage of Commenting Area+

\begin{tabular}{|c|c|c|c|c|}
\hline \multicolumn{2}{|c|}{ Conumenling Arca } & \multirow{2}{*}{$\begin{array}{l}\text { F.FT. Grump } \\
\text { Percentage (\%) }\end{array}$} & \multicolumn{2}{|c|}{ NS Grinrp } \\
\hline & Occurrence & & Oscurrence & Hercentage $(\%)$ \\
\hline Global & 603 & 42 & 890 & $56.3+$ \\
\hline IAIL' & 832 & 58 & 690 & 43.7 \\
\hline
\end{tabular}

'lable 2: The occureuce and Percentage of Commenting Nature

\begin{tabular}{|c|c|c|c|c|}
\hline \multicolumn{2}{|l|}{ Commenling Naa tur } & FFI. Ğणцा & \multicolumn{2}{|c|}{ KS Give } \\
\hline & Occulence & Percenlage $(\%)$ & Occintence & Percentage $(\%)$ \\
\hline Revisim-micnules & 188 & 31 & 1106 & 69.9 \\
\hline Vtr1-revisitn1-trricmlet & 917 & 66 & 171 & 30.1 \\
\hline
\end{tabular}

As Table 2 demonstrated, revision-oriented comments in EFL group accounted for only $34 \%$, which is significantly lower than NSE group (69.9\%). Look at the following students' comments:

EFL group :

A1) What you write inspires me to see this film and you really raise a new topic that people didn't pay attention to.

B1) Personally, I think the topic of the first and second paragraph changes too suddenly.It is more appropriate to add some transitional sentences between them.

NS group:

A2) Most of the time, you frames your quotations well, I thought you executed your quotation excellently in paragraph four when you were quoting your roommates.

B2) However, maybe you might want to describe the contexts of the quotes more in-depth.

It is interesting to note that the two groups were somewhat similar in the nature of comments. Revision-oriented comments are either negative (see B1) or neutral comments (see B2); While non-revision-oriented peer comments were 
primarily positive comments, either complimentary or motivating (see $A 2$ ), neutral comments were rarely found, $A 1$ was an exception.

EFL group was different from NS group in that the quantity of complimentary non-revision-oriented comments in EFL group $(41.9 \%)$ was obviously larger than that in NS group $(23.5 \%)$. This finding reflected, to some extent, the inadequate inter-language development of Chinese EFL learners, which resulted in lack of attention paid to some deeplevel problems, such as lay-out, text organization, cohesion and coherence; Nevertheless, they showed a keen insight into some surface-level issues, such as grammar, vocabulary and punctuation. Therefore, lack of insights into deep-level linguistic issues partly accounted for the frequent occurrence of complimentary comments. In addition, the conception of "harmony", "solidarity" embedded in traditional Chinese culture and ideology partly contributed to this finding. As Nelson and Carson (1998) pointed out, students with collectivist cultural background, for instance, Chinese or Japanese students paid much attention to opinions of the majority, avoiding divergences arising from peer correction suggestions.

As observed from Table 3, both NS group and EFL group tend to employ evaluation type of comment most frequently; however, the NS group (44\%) employed more evaluative comments than their Chinese counterparts (36.2\%). This result further supported Zhu's finding that native speakers provided more evaluative remarks on peer writing than nonnative speakers.

The percentages of alteration type employed by two groups are quite approximate (14.5\% Vs $17 \%)$. The largest differences lied in clarification type, EFL group (32\%) employed much more than NS group (2\%); Moreover, significant differences were observed in the employment of suggestion type of comments, the occurrence of suggestion type comments in NS group is almost double that adopted by the EFL group. These findings led support to the conclusion in Zhu (2001)'study, who argued that non-native speakers tended to pointed out (announcing) and imply (questioning) problematic areas when providing feedback while native speakers tended to provide suggestion more directly through advising(suggesting).

Table 3: The Ocsurence aud Pcreculage of Conmenting Type

\begin{tabular}{|c|c|c|c|c|}
\hline \multicolumn{2}{|c|}{ Commenting 'Iype } & \multirow{2}{*}{$\begin{array}{l}\text { LلL Growp } \\
\text { Peccenlage }(\%)\end{array}$} & \multicolumn{2}{|c|}{ Nos Group } \\
\hline & Occurence & & Oecintence & Pcreculasy $(\%)$ \\
\hline Fvalualion & 520 & .36 .2 & 695 & 44. \\
\hline clarificalion & 159 & 32 & 32 & 2 \\
\hline Snggestion & 218 & 17.3 & 585 & 37.1 \\
\hline Alteration & 208 & 11.5 & 26.8 & $17 \%$ \\
\hline
\end{tabular}

Table 4: The Distribution of 9 Types of Peer Comments

\begin{tabular}{lcrrrrrrrr}
\hline EFL Group & GNE & LRS & GNC & LNC & LNS & GNS & GRS & GRE & LRA \\
\hline Occureuce & 439 & 359 & 159 & 159 & 80 & 40 & 40 & 40 & 0 \\
Percentage $(\%)$ & 30.6 & 25 & 11.1 & 11.1 & 5.6 & 2.8 & 2.8 & 2.8 & 0 \\
NS Group & & & & & & & & & \\
Occurrence & 506 & 442 & 0 & 0 & 0 & 0 & 316 & 0 & 316 \\
Percentage (\%) & 32 & 28 & 0 & 0 & 0 & 0 & 20 & 0 & 20 \\
\hline
\end{tabular}

As revealed in Table 4, EFL group learners employed 8 different types of peer comments, while NS group learners only employed 4 types. This finding showed great divergence with that of Chang's (2002) study, which identified 16 different types of peer comments generated by Taipei University students via three communication modes. Personally, I felt that different participants and peer review modes probably accounted for the divergences in research findings.

Peer comments mainly clustered in GNE and LRS type, taking up over $55 \%$ of overall comments in each group. Both group of learners employed global and revision-oriented suggestion comments on surface-level issues during peer review process. It is interesting to notice that NS group employed much more LRA and GRS comments than their Chinese counterparts, which confirmed the validity of data in the previous Table 1 . The finding revealed that NS learners were more inclined to make GRS type comments than their Chinese counterparts. Surprisingly, the occurrence of LRA in EFL group is almost 0, lagging far behind the NS group learners. It was possibly due to the fact that EFL learners' current linguistic competence and textual competence were far from enough to propose appropriate alterative to those problems they identified in peer's writing, they were prone to resort to "classification" to imply their disagreement. For instance, "what do you mean by...?", "is it what you mean that ...?" are uttered to validate whether writer's purpose was in line with peer reader's inference. Compared with NS learners, EFL learners appeared to be less confident in their writing, they appeared to be prudent in making comments. This happened to justify the frequent occurrence of GNC, LNC type demonstrated in EFL group, but also display the function of "clarification" while commenting in their target language. "Clarification" was employed as a speech act strategy by interlocutors to avoid their positive face being threatened (Brown \& Levinson, 1978). 


\subsection{The Pragmatic Differences of Peer Comments}

\subsubsection{Adoption of "Politeness strategy" and "Face strategy"}

In a paper entitled "Universals in Language Usages: politeness phenomenon", Brown \& Levinson initially mentioned the term of "face". Later, they argued "face" could be categorized into "positive face" and "negative face". The former reflected people's expectations for permission and endorsement, the latter reflected the psychological state in which people long for freedom, reluctant to lose face for being interfered. Findings reported two groups of learners made negative comments to correct errors in peer's essay, but they varied in using "Mood" to adjust their voice. Chinese students preferred to employ declarative or interrogative mood to air their opinions, while American peers would rather combine declarative and imperative mood in their comments, which is employed as the "negative face" strategy by speakers to alleviate the damage face-threatening act might bring about.

C1) I think the suggestion part may not be enough in this analysis.

C2) The tense is inconsistent in paragraph three.

C3) I have a question here, the title is code-switching, but here you have written a lot about foreign effect. Then what foreign effect has to do with code-switching? What is your definition of code-switching? (EFL)

In C1) and C2), declarative mood was employed to point out errors and weaknesses in peer's writing, but in C3), the writer employed two interrogative mood introduced by 'what' to raise question to writer, aiming to emphasize the issue of "deviance of contents" from topic. The interrogative mood increased the force of criticism, but it sounded too blunt, the speech act went against the "politeness theory" and "face-saving theory", posing potential threats to hearer's positive face.

D) As far as organization goes, I think you had well-divided and presented content. However, you might want to consider mentioning the main topic of the paper, online shopping, a little more directly before you jump into ....That way, readers will have a better preview of the rest of the paper. (NS)

The above sentence D) was selected from NS group learners. The student acknowledged peer writer's strengths in organization using declarative sentence, he/she then shifted the focus to negligence in lay-out, then put forward favorable suggestion for revision using imperative sentence. The student used "might", "a little" to undermine the force of criticism. The application of "modality" and "graduation" system broke the ice in communication. It not only presented critical suggestion indirectly, but also undermined the damage of face-threatening to hearers, preventing hearers' negative face from being lost.

\subsubsection{Differences in Clarity of Peer Comments}

The peer comments produced by Chinese EFL learners are more evasive than that of NS learners. Sperber \& Wilson proposed "relevance theory" in their book entitled 'Relevance: communication \& cognition'. Within the relevance theoretical framework, communication is considered as cognitive activity involving explication and inference process. Speakers attempt to achieve the best communication effect by uttering what is most related to the present context. In other words, the less cognitive effort hearer makes in understanding and responding, the more successful the communication will be. It is surprising to notice that peer comments produced by Chinese students were rather vague and over-general, lacking specific, detailed suggestion for revision. For example,

E) As for the structure, actually I am a little confused about the theme and sequence marker in your essay, I can't work out the outline of it. Can you explain how you order your article? Still some quotes of the scene of the film seem not to have much to do with the theme. (EFL)

E) was abstracted from peer comments produced by a Chinese student. It mentioned the student's confusion about the theme and structure without any specific revision suggestion. In addition, the reference of "some quotes" is too vague for student writers to identify which quotes it referred to. All these evasive expressions increased student writers' cognitive workload, preventing writers from making follow-up revisions. As a result, communication via written feedback was liable to break down.

Min (2005) identified four prominent characteristics of comments reported to facilitate students' revision in previous research. 1)clarifying writer's intentions;2) identifying problems;3)explaining the nature of problems;4) making specific suggestions. By comparing student's peer comments, I found that the majority of Chinese EFL learners in my study did not explain the nature of problems. They either identified the root of the problems, or put forward some revision suggestion or alterative. Nevertheless, they did not touch upon the issues of "why do we need to revise in this way?", nor provide adequate justification. Take the following sentences for an instance:

F1)In the first paragraph, I think you should have a comprehensive notion of the novel before your analysis for this novel, so you should use the words. (EFL)

F2)Although the word "stuff" is grammatically and functionally correct in this sentence, I wouldn't use it in a formal paper or essay because it is too vague of a word. A better word to use would be "duties" or "tasks". This is an example where a word is functionally correct but stylistically wrong. (NS)

F1) pointed out the incompleteness of structure, "You need to have a comprehensive notion of the novel before your analysis for this novel". But issues concerning "why is it necessary to introduce the plot of the novel?", "how will it affect the layout of the writing?", were not mentioned at all. By contrast, F2) gave a detailed and convincing exposition 
on the nature of problem, it hit the key points of problems in brief and concise words, that is to say, the words were not used in proper context, the diction appeared to be in conflict with the style of writing.

\section{Conclusion}

According to the findings of the current study, major differences of peer comments between NS group and EFL group were found to be in the following aspects: 1) In terms of commenting area, students would balance local and global features of peer's writing in web-based peer comments. On the whole, EFL group learners were prone to comment more on local features, while NS group preferred to comment on global features; 2) As far as commenting nature is concerned, revision-oriented comments occurred more frequently in NS group(69.9\%) than that in EFL group(34\%). On the contrary, $41.9 \%$ of non-revision-oriented comments in EFL group were complimentary, which was much higher than that in NS group (23.5\%). EFL learners' inter-language proficiency partly contributed to this finding. Besides, the conception of "harmony" and "“solidarity" embedded in traditional Chinese culture and ideology was possibly an underlying contributing factor; 3) From the perspective of commenting types, two groups of learners behaved most sharply in "clarification", followed by "suggestion". However, some similarities were identified as well. The occurrences of "evaluation" and "alteration" are quite approximate. Besides, both groups of learners preferred to apply GNE and LRS in commenting on peer's essay. But, LRA and GRS occurred more frequently in NS group than EFL group. These findings were most likely to be attributed to the fact that EFL learners' current language competence and textual competence were far from enough to afford appropriate alterative or effective revision suggestion. Therefore, they were inclined to resort to "clarification" to save their positive face. This happened to account for the dense distribution of GNC and LNC type of comments in both groups.

The major pragmatic differences of peer comments were summarized as follows: 1) First, NS learners were more skillful at adopting "politeness strategy" and "face-saving strategy" than Chinese counterparts, they were adept in settling communication disputes resulting from the corrective feedback; 2) The peer comments of EFL group were more evasively made than that of NS group, which increased readers' cognitive workload and hampered the progress of successful communication. The descriptions of the problems were over-generalized and evasive, lacking in-depth explanation and specific suggestion for revision.

Through the above comparative analysis, we were able to gain keen insights into the pragmatic differences between Chinese EFL learners' peer comments and Native Speaker learners; Besides, Chinese EFL students' weaknesses in textual construction, discourse organization and rhetoric are exposed as well. Linguistic and pragmatic failures arising from inter-language development were closely related to traditional Chinese culture and ideology. It undermined the quality and effectiveness of intercultural peer comments vicariously. The present study afforded us lessons for peer review training program, providing pedagogical implications for L2 writing.

The current study suffers from limitations that need to be addressed in future research. Firstly, it employed a small, randomized sample, only a small number of participants are involved (25 Chinese students and 30 American students), which was likely to minimize the generalization to a larger population. Another limitation was that the present research adopted the method of descriptive study and mere textual analysis is employed, which might affect the reliability and credibility of the research results. To further examine the intercultural differences of mixed peer group members, the follow-up online interview with individual group members or teacher-student video conference might be needed to help teachers to keep track of learners' strengths and weaknesses in pragmatic competence during peer review activity; thus corresponding peer review training strategies might be implemented to improve learners' performance in providing peer feedback. On the other hand, meaningful negotiation with teachers and peers were likely to raise their consciousness of linguistic, pragmatic and rhetoric problems in their essays and directions for revising drafts. Future research may take into account these issues to improve the effectiveness of the current study.

\section{Acknowledgements}

I wish to thank the editors and anonymous reviewers for their insightful comments and valuable suggestions on an earlier version of this paper. I also acknowledge the financial support from National Open university of China for the Youth Talent Project entitled “An Empirical Study of Blog-assisted Second Language Writing”(Project code: Q2809A) and Guangdong Radio and Television University for the branch program entitled "Exploring Learning-oriented Writing Assessment Paradigm"'(Project code:YJ1306)

\section{References}

Braine, G. (2001). A Study of English as Foreign Language (EFL) writers on a local-area network and in traditional classes. Computers and Composition, 18(3), 275-292. http://dx.doi.org/10.1016/S8755-4615(01)00056-1

Breuch, L. (2004). Virtual Peer Review: Teaching Learning about Writing in Online Environments. Albany, NY: State University of New York press.

Chang, C. F. (2012). Peer review via three modes in an EFL writing course. Computers and Composition, 29, 63-78. http://dx.doi.org/10.1016/j.compcom.2012.01.001

Chen, K. T. C. (2012). Blog-based peer reviewing in EFL writing classrooms for Chinese speakers. Computers and

Composition, 29, 280-291. http://dx.doi.org/10.1016/j.compcom.2012.09.004 
DiGiovanni, E., \& Nagaswami, G. (2001). Online peer review: an alterative to face-to face? ELT Journal, 55(3), 263272. http:// dx.doi:10.1093/elt/55.3.263

Ferris, D., \& Hedgecock, J. (1998).Teaching ESL Composition: Purpose, Process and Practice. Mahawah, NJ: Lawrence Erlbaum.

Guardado, M., \& Shi, L. (2007). ESL students' experiences of online peer feedback. Computers and Composition, 24(4), 443-461.http://dx.doi.org/10.1016/j.compcom.2007.03.002

Liou, H. C.,\& Peng, Z. Y.(2009). Training effects on computer-mediated peer review. System, 37, 514-525. http:.//doi:10.1016/j.system.2009.01.005

Liu, J \& Sadler, R.W. (2003).The effect and affect of peer review in electronic versus traditional modes on L2 writing. Journal of English for Academic Purposes, 2,193-227. http://dx.doi.org/10.1016/S1475-1585(03)00025-0

Mangelsdorf, K.,\&Schlumberger,A.(1992). ESL student response stances in a peer-review task. Journal of Second Language Writing, 1, 235-254. http://dx.doi.org/10.1016/1060-3743(92)90005-A

Min, H. T. (2005).Training students to become successful peer reviewers. System, 33(2), 293-308. http://dx.doi.org/10.1016/j.system.2004.11.003

Min, H. T. 2006.The effects of trained peer review on EFL students: revision types and writing quality. Journal of Second Language Writing, 15, 118-141. http://dx.doi.org/10.1016/j.jslw.2006.01.003,

Mittan, R. (1989). The Peer Review Process: Harnessing Students' Communicative Power. New York, NY: Longman.

Nelson, G. .L. ,\& Carson, J. G. (1998). ESL students' perceptions of effectiveness of peer response groups. Journal of Second Language Writing, 7, 113-131. http://dx.doi.org/10.1016/S1060-3743(98)90010-8

Nelson, G. L. ,\&Murphy, J. M. (1992). An L2 writing group: task and social dimensions. Journal of Second Language Writing, 1,171-193.http://dx.doi.org/10.1016/1060-3743(92)90002-7

Stanley, J. (1992). Coaching student writers to be effective peer evaluators. Journal of Second Language Writing, 1 , 217-233. http://dx.doi.org/10.1016/1060-3743(92)90004-9

Tusi, A. ,\& Ng, M. (2000). Do secondary L2 writers benefit from peer comments? Journal of Second Language Writing, 9(2), 147-170. http://dx.doi.org/10.1016/S1060-3743(00)00022-9

Tuzi, F. (2004). The impact of e-feedback on the revisions of L2 writers in an academic writing course. Computers and Composition, 21(2),217-235.http://dx.doi.org/10.1016/j.compcom.2004.02.003

Zhu, W. 2001. Interaction and feedback in mixed peer response group. Journal of Second Language Writing,10,251276. 